\title{
Application of High-Tension Annealing to Nylon 46 Fibers
}

\author{
Akihiro SuzUKI ${ }^{\dagger}$, Akira ENDo, and Toshio KunUgI \\ Department of Applied Chemistry and Biotechnology, Faculty of Engineering, \\ Yamanashi University, 4-3-11 Takeda, Kofu 400-8511, Japan
}

(Received May 6, 1997)

\begin{abstract}
To improve the tensile properties of nylon 46 fibers, high-tension annealing (HTA) was applied to nylon 46 fibers previously treated with high-temperature zone-drawing. Fibers produced by the high-temperature zone-drawing treatment had a tensile modulus of $7.2 \mathrm{GPa}$ and tensile strength of $1.0 \mathrm{GPa}$. Two HTA treatments were carried out; the first (HTA1) treatment at $100^{\circ} \mathrm{C}$ under an applied tension of $538.2 \mathrm{MPa}$, and the second (HTA2) treatment at $150^{\circ} \mathrm{C} \mathrm{under} 568.0 \mathrm{MPa}$. The fibers obtained finally had a tensile modulus of $8.4 \mathrm{GPa}$, tensile strength of $1.2 \mathrm{GPa}$ and a storage modulus of $11.2 \mathrm{GPa}$ at $25^{\circ} \mathrm{C}$. KEY WORDS High-Temperature Zone-Drawing / High-Tension Annealing / Nylon 46 Fiber / High-Modulus /
\end{abstract}

The microstructure and mechanical properties of nylon 6 and nylon 66 fibers have been extensively investigated. In contrast, fewer studies ${ }^{1-7}$ have been made on the mechanical behavior of nylon 46 fiber, particularly improvements of mechanical properties.

To impart superior mechanical properties to nylon fibers, many techniques have been proposed. ${ }^{8-14}$ Hightemperature zone-drawing ${ }^{15-18}$ (HT-ZD) also leads to high-modulus and high-strength fibers. In our previous paper, ${ }^{19}$ the HT-ZD method applied to nylon 46 fibers was introduced and proved itself capable of improving mechanical properties. The resulting HT-ZD nylon 46 fiber had a tensile modulus of $7.2 \mathrm{GPa}$ and a tensile strength of $1.0 \mathrm{GPa}$. The modulus obtained is almost two times that of the commercial nylon 46 fiber. ${ }^{20}$ HT-ZD treatment was found to be effective in producing highmodulus nylon 46 fibers. However, the modulus of the HT-ZD fiber corresponds only to $15 \%$ of the theoretical modulus $^{21}$ ( $E_{1}=48 \mathrm{GPa}$ at room temperature).

HT-ZD can easily highly orient the crystallites in the drawing direction, but is not enough to arrange the amorphous chains in drawing direction. To further improve the mechanical properties of fibers, it is necessary to arrange amorphous chains that play an important role in the determination of the mechanical properties in the drawing direction. However, it is more difficult to develop the orientation of the amorphous chains in an oriented fiber because the segmental mobility of the amorphous chains is severely constrained by crystallites and molecular entanglements that act as physical crosslinks and hydrogen bonds between the chains. ${ }^{22}$

High-tension annealing (HTA) was proposed as a way to further improve the mechanical properties of the fibers highly oriented by zone-drawing and/or zone-annealing. ${ }^{23-26}$ HTA was carried out near an a relaxation temperature under extremely high tension to arrange the amorphous chains in the drawing direction. HTA has been so far applied to the fibers such as poly(ethylene terephthalate) (PET), ${ }^{23}$ poly(vinyl alcohol) (PVA), ${ }^{24}$ nylon $6,{ }^{25}$ and nylon $66^{26}$ fibers, to improve mechanical properties. We reported that amorphous orientation factors of those fibers were found to reach high values by HTA and mechanical properties were further improved. For example, the storage modulus at $25^{\circ} \mathrm{C}$ for each of the HTA PET fiber, ${ }^{23}$ HTA PVA fiber, ${ }^{24}$ HTA nylon $6,{ }^{25}$ and HTA nylon $66^{26}$-all produced using the HTA treatments-was $30,78,21.1$, and $21.7 \mathrm{GPa}$, respectively.

The objective of the present study is to further improve the mechanical properties of nylon 46 fibers using HTA. Microstructural changes occurring during the process have been monitored by wide-angle X-ray diffraction, birefringence, differential scanning calorimetry, shrinkage measurements, and specific gravity.

\section{EXPERIMENTAL}

\section{Material}

The original material used in the present study was as-spun nylon 46 monofilament supplied by UNITIKA Ltd. The original fiber had a diameter of about $0.327 \mathrm{~mm}$ and a degree of crystallinity of $34.8 \%$ and was isotropic and opaque because of a small amount of $\mathrm{TiO}_{2}$.

\section{High-Temperature Zone-Drawing and High-Tension An- nealing Treatments}

The monofilament of the original fiber was initially treated three times with HT-ZD before HTA. HT-ZD was carried out using the apparatus described previously. ${ }^{19}$

A schematic diagram of the apparatus used for HTA is given in Figure 1. It consists of a load cell connected to a recorder, electric furnace of a $20 \mathrm{~mm}$ long, and Linead motor (Oriental Motor Co., Ltd.) which consists

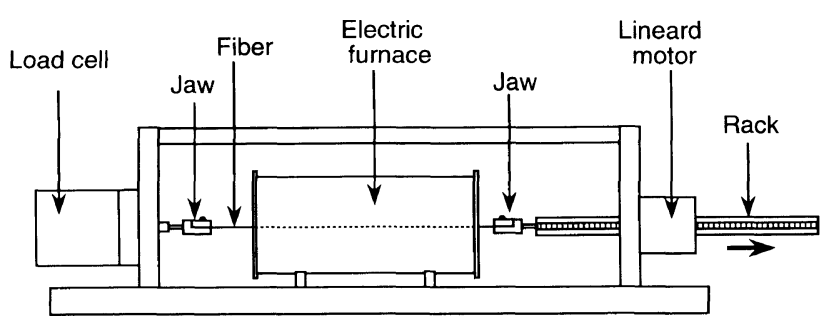

Figure 1. Apparatus for the high-tension annealing.

\footnotetext{
${ }^{\dagger}$ To whom correspondence should be addressed. (Tel: $+81-552-20-8556$, Fax: $\left.+81-552-20-8554\right)$.
} 
of a rack-and-pinion unit and a speed controller. The rack-and-pinion unit converts rotational motion of the motor into linear motion. One end of a fiber was fixed at a jaw equipped with the load cell, and the other was run through a heater and fixed at a jaw equipped with the edge of the rack, and the fiber was drawn at constant speed. When the temperature of the electric furnace reached the desired treating temperature, the fiber was drawn at a speed of $10 \mathrm{~mm} \mathrm{~min}^{-1}$. When the tension applied to the fiber reached a desired value which is in the range of 70 to $90 \%$ of the strength at the break $\left(\sigma_{b}\right)$, the stretching was stopped, and then the fiber was kept at constant length for a given time. This desired value is called the initial applied tension and designated as $\sigma_{0}$. $\sigma_{\mathrm{b}}$ was previously estimated from the stress-strain curve recorded at the same temperature as the desired treatment temperature.

\section{Measurement}

The draw ratio was determined in the usual way by measuring the displacement of ink marks placed $10 \mathrm{~mm}$ apart on the fiber before drawing. The density of the fiber was measured at $23^{\circ} \mathrm{C}$ by flotation using a mixture of toluene and carbon tetrachloride.

Differential scanning calorimetry (DSC) measurements were carried out using a Rigaku DSC 8230C calorimeter to determine the degree of crystallinity $\left(X_{\mathrm{c}}\right)$ and melting temperature of the fiber. DSC scaning was performed within the temperature range from 25 to $300^{\circ} \mathrm{C}$, using a heating rate of $10^{\circ} \mathrm{C} \mathrm{min}^{-1}$ in a nitrogen gas atmosphere. The degree of crystallinity $\left(X_{c}\right)$ was calculated by the following equation:

$$
X_{\mathrm{c}}=\left(\Delta H_{\mathrm{f}} / \Delta H_{0}\right) \times 100
$$

where $\Delta H_{\mathrm{f}}$ is the heat of fusion for sample, and $\Delta H_{0}$ is the heat of fusion $\left(\Delta H_{0}\right)$ for completely crystalline nylon $46, \Delta H_{0}=210 \mathrm{~J} \mathrm{~g}^{-1} .^{27}$

Thermal shrinkage was measured with a Rigaku SSTMA at a heating rate of $5^{\circ} \mathrm{Cmin}^{-1}$. Samples with a $15 \mathrm{~mm}$ gauge length between two jaws were held at a tension of $5 \mathrm{~g} \mathrm{~cm}^{-2}$, the minimum tension to stretch a fiber tightly.

The orientation factors of crystallites $\left(f_{\mathrm{c}}\right)$ were evaluated using the Wilchinsky ${ }^{28}$ method from wide-angle X-ray diffraction patterns. $f_{\mathrm{c}}$ was estimated using a (100) plane.

Apparent crystallite size was estimated from the broadening of the diffraction peaks by applying Scherrer's equation:

$$
D_{h k l}=0.9 \lambda / \beta \cos \theta_{h k l}
$$

where $D_{h k l}$ is crystallite width normal to $(h k l)$ plane, $\lambda$ is the X-ray wavelength $(1.542 \AA), \theta_{h k l}$ is the Bragg angle of the $(h k l)$ plane, and $\beta$ is the observed half-width of the peaks corrected for a instrumental broadening.

Tensile properties were determined with a Tensilon tensile testing machine (Orientec Co., Ltd.). Tensile modulus, tensile strength, and elongation at the break were determined from the stress-strain curves obtained at $25^{\circ} \mathrm{C}$, RH $65 \%$. The measurements were carried out using a gauge length of $5.0 \mathrm{~cm}$ and a crosshead speed of $0.5 \mathrm{~cm} \mathrm{~min}^{-1}$. The dynamic viscoelastic properties were measured at $3.5,11,35$, and $110 \mathrm{~Hz}$ with a dynamic
Table I. Optimum conditions for

\begin{tabular}{|c|c|c|c|}
\hline Treatment & $\begin{array}{c}\text { Treating } \\
\text { temperature }\end{array}$ & $\begin{array}{l}\text { Applied } \\
\text { tension }\end{array}$ & $\begin{array}{l}\text { Heater } \\
\text { speed }\end{array}$ \\
\hline & ${ }^{\circ} \mathrm{C}$ & $\mathrm{MPa}$ & $\mathrm{mm} \min ^{-1}$ \\
\hline HT-ZD1 & 200 & 27.0 & 30 \\
\hline HT-ZD2 & 225 & 117 & 30 \\
\hline HT-ZD3 & 230 & 245 & 30 \\
\hline
\end{tabular}
HT-ZD treatments

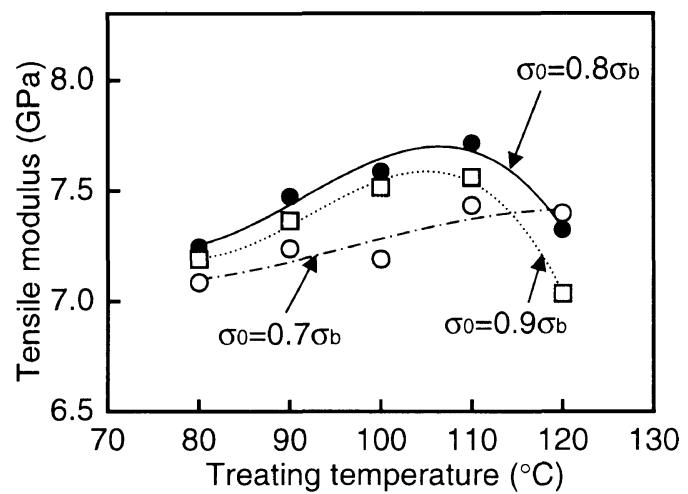

Figure 2. Changes in the tensile modulus of fibers at various applied tensions with treating temperature: $(\bigcirc), \sigma_{0}=0.7 \sigma_{\mathrm{b}} ;(\bigcirc), \sigma_{0}=0.8 \sigma_{\mathrm{b}}$; $(\square), \sigma_{0}=0.9 \sigma_{\mathrm{b}}$

viscoelastometer VIBRON DDV-II (Orientec Co., Ltd.). Measurements were carried out over a temperature range of 25 to about $250^{\circ} \mathrm{C}$ at an interval of $5^{\circ} \mathrm{C}$, and the average heating rate was $2^{\circ} \mathrm{C} \mathrm{min}^{-1}$. A fiber was held at $20 \mathrm{~mm}$ gauge length between two jaws.

Activation energy $\left(\Delta H_{\mathrm{a}}\right)$ was estimated using the following equation:

$$
\frac{f_{1}}{f_{2}}=\frac{\Delta H_{\mathrm{a}}}{R}\left(\frac{1}{T_{2}}-\frac{1}{T_{1}}\right)
$$

where $f$ is frequency, $T$ is peak temperature of $\alpha$ dispersion in temperature dependence of loss modulus $\left(E^{\prime \prime}\right)$, and $R$ is the gas constant.

\section{RESULTS AND DISCUSSION}

\section{Optimum Conditions of High-Tension Annealing}

The original nylon 46 fiber was initially drawn with HT-ZD before HTA. HT-ZD was carried out in three steps under the same optimum conditions as in our previous paper, ${ }^{19}$ given in Table I. These treatments produced a fiber whose crystallinity was $55.6 \%$ and a tensile modulus, 7.2 GPa.

HTA was carried out in two steps. The optimum conditions for the first step (HTA1) were determined from the relation between treating temperature $\left(T_{\text {HTA }}\right)$ and tensile modulus of the fibers treated under different initial applied tensions $\left(\sigma_{0}\right)-70 \%\left(=0.7 \sigma_{\mathrm{b}}\right), 80 \%$ $\left(=0.8 \sigma_{\mathrm{b}}\right)$, and $90 \%\left(=0.9 \sigma_{\mathrm{b}}\right)$ of strength at the break $\left(\sigma_{\mathrm{b}}\right)$-as shown in Figure 2. The condition for giving the maximum modulus was chosen as an optimum one for HTA1. $\sigma_{b}$ was previously estimated from the stressstrain curve recorded at the same temperature as the given $T_{\mathrm{HTA}}$. When $T_{\mathrm{HTA}}=110^{\circ} \mathrm{C}$ and $\sigma_{0}=0.8 \sigma_{\mathrm{b}}(=538$ $\mathrm{MPa}$ ), the tensile modulus shows the maximum value. 
The optimum conditions for the second step (HTA2) were determined in the same manner as above. The optimum conditions for each HTA treatment are given in Table II. The optimum treating time for each step was $30 \mathrm{~min}$. Microstructure and mechanical properties of the fiber obtained under the respective optimum conditions are described below.

\section{Microstructures of HT-ZD and HTA Fibers}

Table III shows the draw ratio $(\lambda)$, density $(d)$, degree of crystallinity $\left(X_{\mathrm{c}}\right)$, crystallite orientation factor $\left(f_{\mathrm{c}}\right)$, and apparent crystallite size normal to the (100) and $(010)$ planes $\left(D_{100}\right.$ and $\left.D_{010}\right)$ for each fiber. $X_{\mathrm{c}}$ increased from $34.8 \%$ for the original fiber to $55.8 \%$ for the HT-ZD3 fiber. Although $T_{\text {HTA }}$ in HTA2 was $115^{\circ} \mathrm{C}$ lower than a crystallization temperature $\left(T_{\mathrm{c}}\right)$ of $265^{\circ} \mathrm{C}$ for nylon $46, X_{\mathrm{c}}$ increased up to $58.8 \%$ in the course of HTA. Such increase shows that the highly oriented amorphous chains easily crystallized even at temperatures much lower than the $T_{\mathrm{c}}$. Crystallization in an oriented material is very much faster than that in its isotropic one. ${ }^{29-31} X_{\mathrm{c}}$ of the HTA2 fiber is larger than that of the HTA nylon 6 fiber reported in the previous paper. ${ }^{25}$ The difference in $X_{\mathrm{c}}$ between nylon 46 and nylon 6 originated from a highly symmetrical molecular structure and fairly high amide groups content per unit length of chain for nylon 46 compared with those for the nylon $6 .^{32}$ Although $X_{\mathrm{c}}$ increased during treatment, crystallite sizes $\left(D_{100}\right.$ and $D_{010}$ ) held constant at about $28 \AA$ throughout HT-ZD and subsequent HTA treatments. It can be, therefore, considered that the increase in the $X_{\mathrm{c}}$ shows the evolution of crystallization along the drawing direction although there are no data about crystallite size perpendicular to the $c$-axis, that is, drawing direction. In fact, Peszkin et al. reported that further development of crystallization occurred along the fiber axis of the already-oriented crystals. ${ }^{33} f_{\mathrm{c}}$ increased dramatically up to 0.949 during the HT-ZD1 treatment and slightly during subsequent treatment. In HT-ZD, the crystallite may be grown direction because the zone-heater moves

Table II. Optimum conditions for HTA treatments

\begin{tabular}{|c|c|c|c|}
\hline Treatment & $\begin{array}{c}\text { Treating } \\
\text { temperature }\end{array}$ & $\begin{array}{l}\text { Applied } \\
\text { tension }\end{array}$ & $\begin{array}{c}\text { Treating } \\
\text { time }\end{array}$ \\
\hline & ${ }^{\circ} \mathrm{C}$ & $\mathrm{MPa}$ & $\min$ \\
\hline HTA1 & 110 & $538\left(=0.80 \sigma_{\mathrm{b}}\right)$ & 30 \\
\hline HTA2 & 150 & $568\left(=0.80 \sigma_{\mathrm{b}}\right)$ & 30 \\
\hline
\end{tabular}

in the fiber direction. Murthy et al. ${ }^{34}$ reported that the crystalline orientation increased rapidly at small draw ratio $(<3)$ and reached a plateau at higher draw ratio.

Figure 3 shows the DSC curves for the original, HT ZD, and HTA fibers. The original fiber has a double melting peak $\left(270^{\circ} \mathrm{C}\right.$ and $\left.283^{\circ} \mathrm{C}\right)$. The peak at $270^{\circ} \mathrm{C}$ can be attributed to melting of crystals in the original fiber, and that at $283^{\circ} \mathrm{C}$ to melting of the recrystallized crystals with a higher perfection during DSC scanning. ${ }^{35,36}$ The HT-ZD1 fiber had an endotherm with a peak temperature of $277^{\circ} \mathrm{C}$ and a shoulder on the higher temperature side of the peak. The shoulder is observed at the same temperature as that at the higher melting peak of the original fiber. However, in the DSC curves for the HT-ZD2, HT-ZD3, and HTA fibers, no shoulders are observed other than a sharp single peak. The melting peak shifts toward a higher temperature and becomes sharper with processing. The melting peak of the HTA2 fiber is located at $285^{\circ} \mathrm{C}$, which is $2^{\circ} \mathrm{C}$ higher than the high melting peak of the original fiber. The shift of the melting peak toward higher temperatures implies an increase in crystal size. ${ }^{37}$

Figure 4 shows the TMA curves for the original, HT-ZD1, HT-ZD3, and HTA2 fibers. The original fiber expands as temperature rises, whereas the HT-ZD and

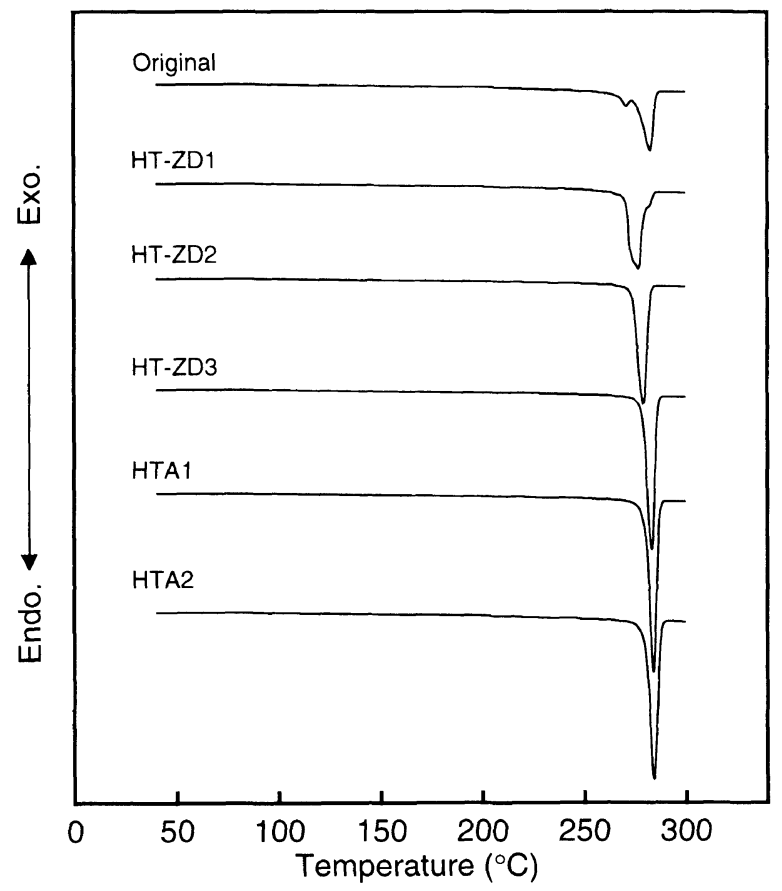

Figure 3. DSC curves for the original, HT-ZD, and HTA fibers.

Table III. Draw ratio $(\lambda)$, density $(d)$, crystallinity $\left(X_{\mathrm{c}}\right)$, crystallite orientation factor $\left(f_{\mathrm{c}}\right)$, and crystallite sizes $\left(D_{h k l}\right)$ of $(100)$ and $(010)$ planes for the original, HT-ZD and HTA fibers

\begin{tabular}{|c|c|c|c|c|c|c|}
\hline \multirow{2}{*}{ Fiber } & \multirow{2}{*}{$\lambda$} & \multirow{2}{*}{$\frac{d}{\mathrm{gcm}^{-3}}$} & \multirow{2}{*}{$\frac{X_{\mathrm{c}}}{\%}$} & \multirow{2}{*}{$f_{\mathrm{c}}$} & $D_{100}$ & $D_{010}$ \\
\hline & & & & & \multicolumn{2}{|c|}{$\AA$} \\
\hline Original & - & 1.173 & 34.8 & - & - & - \\
\hline HT-ZDI & 3.9 & 1.176 & 44.2 & 0.949 & 28.8 & 26.1 \\
\hline HT-ZD2 & 4.4 & 1.176 & 48.8 & 0.951 & 28.9 & 28.9 \\
\hline HT-ZD3 & 5.6 & 1.178 & 55.6 & 0.961 & 28.8 & 29.9 \\
\hline HTA1 & 5.6 & 1.179 & 58.6 & 0.961 & 27.9 & 28.9 \\
\hline HTA2 & 5.7 & 1.179 & 58.8 & 0.959 & 26.9 & 27.9 \\
\hline
\end{tabular}




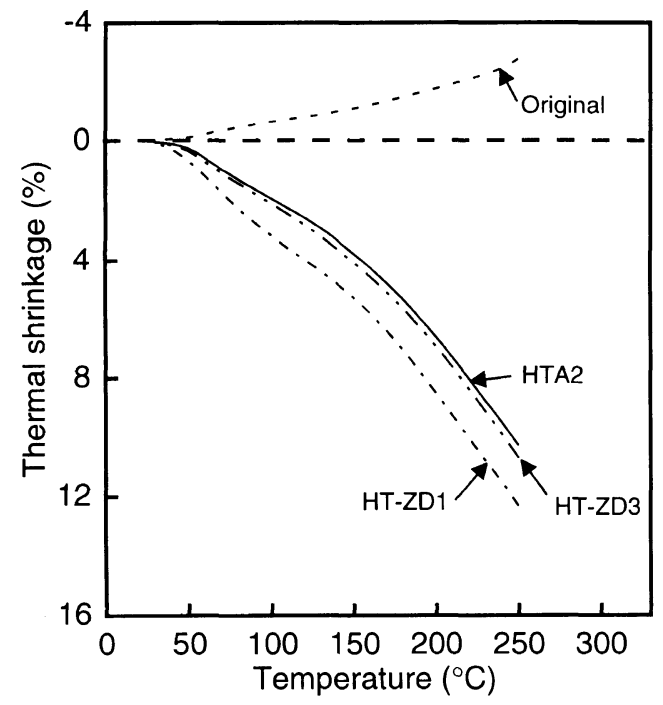

Figure 4. Temperature dependence of shrinkage for the original, HT-ZD, and HTA fibers: (--), original; (-- - , HT-ZD 1; (--- ), HT-ZD3; (-), HTA2.

Table IV. Thermal shrinkage (St) at $200^{\circ} \mathrm{C}$ for the original, HT-ZD, and HTA fibers

\begin{tabular}{lr}
\hline Fiber & St $/ \%$ \\
\hline Original & -1.8 \\
HT-ZD1 & 8.5 \\
HT-ZD2 & 7.2 \\
HT-ZD3 & 6.9 \\
HTA1 & 6.9 \\
HTA2 & 6.6 \\
\hline
\end{tabular}

HTA fibers shrink. Thermal shrinkage during heating is associated with the chain folding in the amorphous regions. ${ }^{38}$ In spite of the temperature range below a glass transition temperature, the treated fibers shrink with increasing temperature. This indicates that there occurred small rubber-elastic contraction of tie molecules above the subglass transition temperature $(\beta$ relaxation at $\left.-73^{\circ} \mathrm{C}\right)$. In $\beta$ relaxation, the non-hydrogen bonded amide groups begin to move, but this is not sufficient to overwhelm the expansion of the adjacent amorphous components. ${ }^{39}$ The thermal shrinkage at $200^{\circ} \mathrm{C}$, as shown in Table IV, decreases from $8.5 \%$ for the HT-ZD1 fiber to $6.6 \%$ for the HTA2 fiber. This implies that amorphous chains are locked into crystallites and no refolding may occur. In other words, the decrease in shrinkage with processing is probably attributed to increase in the crosslink density of the network built-up by the crystallites.

\section{Mechanical Properties of HT-ZD and HTA Fibers}

Table $\mathrm{V}$ shows the tensile properties for the original, HT-ZD and HTA fibers obtained under optimum conditions. Tensile modulus and strength increase stepwise with processing. The HTA2 fiber finally obtained has a tensile modulus of $8.4 \mathrm{GPa}$ and a tensile strength of 1.2 GPa. The tensile modulus of the HTA2 fiber is about twice that of the commercial nylon 46 fibers $^{20}(3.9 \mathrm{GPa})$. However, HTA for nylon 46 fibers was less effective in improving the mechanical properties compared to PET $^{23}$ and nylon $6^{24}$ fibers. It seems reasonable to suppose
Table V. Tensile properties for the original, HT-ZD, and HTA fibers

\begin{tabular}{cccc}
\hline Fiber & $\begin{array}{c}\text { Young's } \\
\text { modulus }\end{array}$ & $\begin{array}{c}\text { Strength } \\
\text { at break }\end{array}$ & $\begin{array}{c}\text { Elongation } \\
\text { at break }\end{array}$ \\
\cline { 2 - 3 } & $\mathrm{GPa}$ & $\mathrm{GPa}$ & $\%$ \\
\hline Original & 1.2 & - & - \\
HT-ZD1 & 5.6 & 0.7 & 24.8 \\
HT-ZD2 & 6.5 & 0.9 & 21.7 \\
HT-ZD3 & 7.2 & 1.0 & 10.3 \\
----1.5 & 1.2 & 14.2 \\
HTA1 & 7.7 & 1.2 & 12.7 \\
HTA2 & 8.4 & & \\
\hline
\end{tabular}

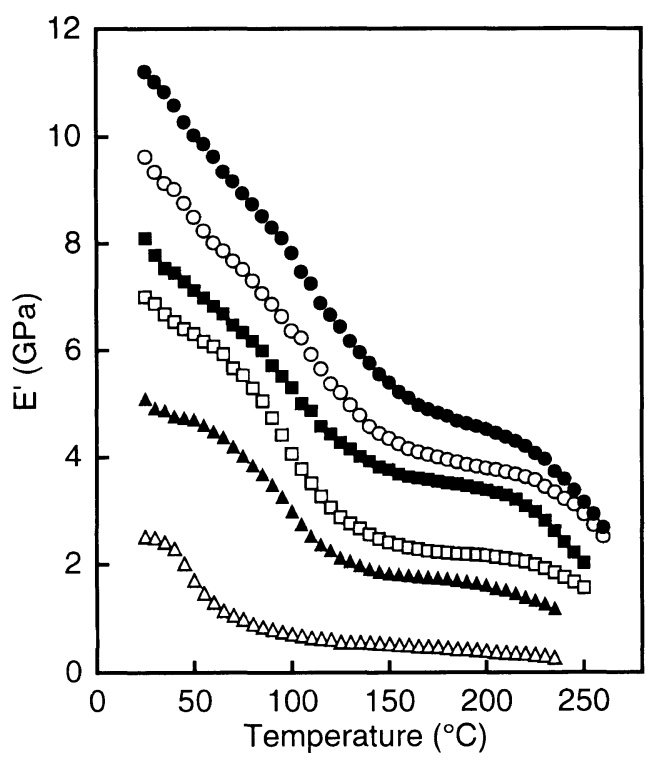

Figure 5. Storage modulus $\left(E^{\prime}\right)$ as a function of temperature at $110 \mathrm{~Hz}$ for the original, HT-ZD, and HTA fibers: $(\triangle)$, original; $(\boldsymbol{\Delta})$, HT-ZDI;

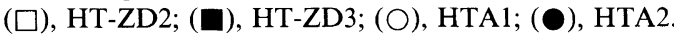

that the amorphous chains are restricted by numerous hydrogen bonds because of fairly high amide group content and could not highly orient, and consequently, HTA for nylon 46 fibers was less effective in improving mechanical properties.

Figures 5 and 6 show the storage modulus $\left(E^{\prime}\right)$ and $\tan \delta$ as functions of temperature at $110 \mathrm{~Hz}$ for the original, HT-ZD, and HTA fibers. $E^{\prime}$ increased stepwise with processing over a wide temperature range. In the HTA2 fiber finally obtained, maximum value at $25^{\circ} \mathrm{C}$ was $11.2 \mathrm{GPa}$, which is higher than $E^{\prime}$ (about $4.5 \mathrm{GPa}$ at room temperature) reported by Kudo et al. ${ }^{6} E^{\prime}$ of all the fibers decreased gradually with increasing temperature, and $E^{\prime}$ of the HTA2 fiber was $4.5 \mathrm{GPa}$ even at $200^{\circ} \mathrm{C}$. In the $\tan \delta$-temperature curve (Figure 6), loss peaks are observed from 75 to $120^{\circ} \mathrm{C}$. The peaks are called $\alpha$ relaxation peaks and originate with rupture of interchain hydrogen bonding due to increase of motion of chain segments in the amorphous regions. ${ }^{40,41}$ The $\alpha$ relaxation peak of the nylon 46 is located at a $10-20^{\circ} \mathrm{C}$ higher temperature than those of other nylons. ${ }^{42}$ The $\alpha$ relaxation peak shifts to a higher temperature, decreases in height, and becomes much broader with processing. HTA2 fiber has a peak value of 0.041 at $120^{\circ} \mathrm{C}$. Changes in position and profile of the loss peak point out that 


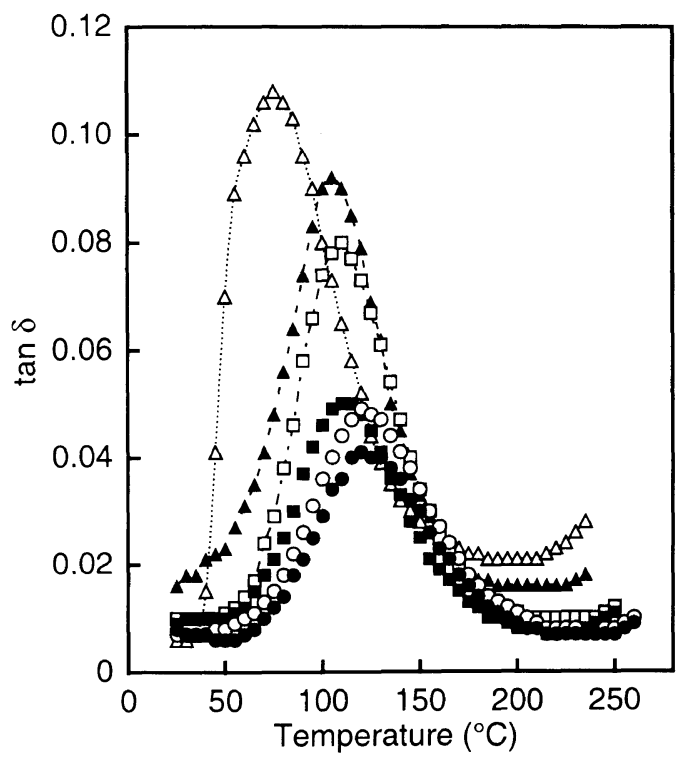

Figure 6. Tan $\delta$ as a function of temperature at $110 \mathrm{~Hz}$ for the original, HT-ZD, and HTA fibers: $(\triangle)$, original; $(\boldsymbol{\Delta})$, HT-ZD1; $(\square)$, HT-ZD2; (ם), HT-ZD3; (O), HTA1; (๑), HTA2.

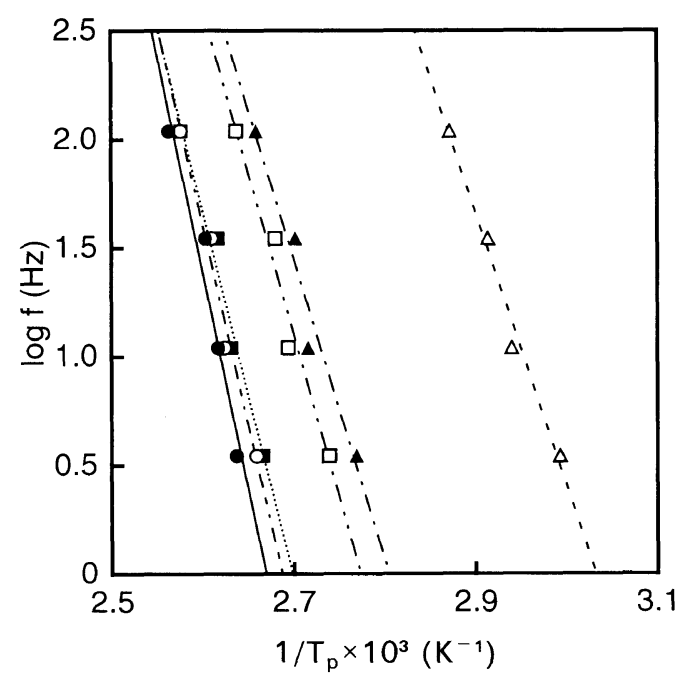

Figure 7. $\log f$ vs. $1 / T_{\mathrm{p}}$ plot for the $\alpha$ dispersion: $(\triangle)$, original; $(\mathbf{\Delta})$,

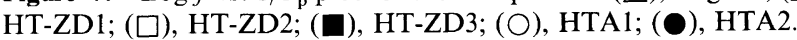

the thermal mobility of amorphous chains is gradually restricted by the surrounding crystallites grown with processing. To estimate the degree of crystallite constraint on amorphous regions, activation energy for the $\alpha$ dispersion was calculated, using the Arrhenius equation, from plots of $\log f v s$. the reciprocal of peak temperature $\left(1 / T_{\mathrm{p}}\right)$, where $T_{\mathrm{p}}$ is the $E^{\prime \prime}$ peak temperature of the $\alpha$ relaxation at frequency $f$, as shown in Figure 7 . Activation energy for each fiber is given in Table VI; the value of HTA2 fiber increased to $91.9 \mathrm{kcal} \mathrm{mol}^{-1}$. Such increase proves that mobility of amorphous chains is restricted by the surrounding crystallites.

\section{CONCLUSIONS}

Our experimental data show that the high-tension annealing treatment is effective for improving the mechanical properties of nylon 46 fibers, and the results are as follows.
Table VI. Activation energy $(\Delta H)$ for the original, HT-ZD, and HTA fibers

\begin{tabular}{cc}
\hline Fiber & $\Delta H / \mathrm{kcal} \mathrm{mol}^{-1}$ \\
\hline Original & 57.9 \\
HT-ZD1 & 63.7 \\
HT-ZD2 & 69.0 \\
HT-ZD3 & 78.1 \\
\hline HTA1 & 84.9 \\
HTA2 & 91.9
\end{tabular}

1. The degree of crystallinity increased to $55.8 \%$ by three HT-ZD treatments and then to $58.8 \%$ by HTA3.

2. The orientation factor of crystallites rose remarkably up to 0.949 with only HT-ZD1.

3. HTA3 fibers showed a tensile modulus of $8.4 \mathrm{GPa}$ and storage modulus of $11.2 \mathrm{GPa}$ at $25^{\circ} \mathrm{C}$. The $\alpha$ peak in the $\tan \delta$-temperature curve shifted to a higher temperature, reducing its magnitude with processing.

Acknowledgments. We are grateful to UNITIKA Ltd. for supplying the nylon 46 fibers.

\section{REFERENCES}

1. E. Roerdink, and J. M. M. Warnier, Polymer, 26, 1582 (1985).

2. R. J. Gaymans, S. Aalto, and F. H. J. Maurer, J. Polym. Sci., Part A, Polym. Chem., 27, 423 (1989).

3. E. D. T., Hill, M., S. K. Hong, A. Keller, and S. Organ, Macromolecules, 25, 917 (1992).

4. P. A. M. Steeman and F. H. J. Maurer, Polymer, 33, 4236 (1992).

5. A. M. W. Butle, B. Folkers, M. H. V. Mulder, and C. A. Smolders, J. Appl. Polym. Sci., 50, 13 (1993).

6. K. Kudo, M. Mochizuki, S. Kiriyama, M. Watanabe, and M. Hirami, J. Appl. Polym. Sci., 52, 861 (1994).

7. P. L. Shah, Polym. Eng. Sci., 34, 759 (1994).

8. S. Gogolewski and A. J. Pennings, Polymer, 26, 1394 (1985).

9. D. Acierno, F. P. La Mantia, G. Polizotti, G. C. Alfonso, and A. Ciferri, J. Polym. Sci., Polym. Lett. Ed., 15, 323 (1977).

10. A. Richardson and I.M. Ward, J. Polym. Sci., Polym. Phys. Ed., 19, 1549 (1981)

11. T. Kanamoto, A. E. Zachariades, and R. S. Porter, J. Polym. Sci., Polym. Phys. Ed., 20, 1485 (1982).

12. H. H. Chuah and R. S. Porter, Polymer, 27, 1022 (1986).

13. T. Kunugi, I. Akiyama, and M. Hashimoto, Polymer, 23, 1193 (1982).

14. T. Kunugi, T. Ikuta, M. Hashimoto, and K. Mastuzaki, Polymer, 23, 1983 (1982).

15. T. Kunugi, J. Polym. Sci., Polym. Lett., 20, 329 (1982).

16. T. Kunugi, T. Kawasumi, and T. Ito, J. Appl. Polym. Sci., 40, 2101 (1990).

17. T. Kunugi, A. Suzuki, and E. Kubota, Kobunshi Ronbunshu, 49, 161 (1992).

18. A. Suzuki, S. Maruyama, and T. Kunugi, Kobunshi Ronbunshu, 49, 741 (1992).

19. A. Suzuki and A. Endo, Polymer, 38, 3085 (1997).

20. M. Mochizuki and K. Kudo, Sen'i Gakkaishi, 47, 336 (1991).

21. T. Nishino, K. Tada, and K. Nakamae, Polym. Prepr., Jpn., 40, 1263 (1991)

22. H. H. Chuah and R. S. Porter, Polymer, 27, 241 (1986).

23. T. Kunugi, A. Suzuki, and T. Tsuiki, Kobunshi Ronbunshu, 48, 703 (1991).

24. A. Suzuki, S. Kawasaki, and T. Kunugi, Kobunshi Ronbunshu, 51, 201 (1994).

25. A. Suzuki, M. Kondo, and T. Kunugi, Kobunshi Ronbunshu, 50, 93 (1993).

26. A. Suzuki, H. Murata, and T. Kunugi, Polymer, 39, 1351 (1998).

27. R. J. Gaymans, "Int. of Polym. Sci. \& Techn.," Vol. 1, Kleintjiens, Ed., Elsevier Sci., Oxford, 1986, p 573.

28. Z. W. Wilchinsky, J. Appl. Phys., 30, 792 (1959). 
29. F. S. Smith and R. D. Steward, Polymer, 15, 283 (1974).

30. G. C. Alfonso, M. P. Verdona, and A. Wasiak, Polymer, 19, 711 (1978).

31. K. M. Gupte, H. Motz, and J. M. Schultz, J. Polym. Sci., Polym. Phys. Ed., 21, 1927 (1983).

32. P. A. M. Steeman and F. H. J. Maurer, Polymer, 26, 1394 (1985)

33. P. N. Peszkin, J. M. Schultz, and J. S. Lin, J. Polym. Sci., Polym. Phys. Ed., 24, 2592 (1986).

34. N. S. Murthy, R. G. Bray, S. T. Correale, and R. A. F. Moore, Polymer, 36, 3863 (1995).

35. T. J. Pecorini and R. W. Hertzberg, Polymer, 34, 5053 (1993).
36. L. Quintanilla, J. C. Rodríguez-Cabello, and J. M. Pastor, Polymer, 35, 2321 (1994).

37. R. J. Gaymans, T. E. C. Van Utteren, J. W. A. Van Der Berg, and J. M. Schultz, J. Polym. Sci., Polym. Chem. Ed., 15, 537 (1977).

38. M. P. W. Wilson, Polymer, 15, 277 (1974)

39. C. L. Choy, W. P. Leung, and E. L. Ong, Polymer, 26, 884 (1985).

40. Y. S. Papir, S. Kapur, C. E. Rogers, and E. Baer, J. Polym. Sci., 10, 1305 (1972).

41. X. Ning and H. Ishida, J. Polym. Sci. Part B, 29, 1479 (1991).

42. P. A. M. Steeman and F. H. J. Maurer, Polymer, 33, 4236 (1992). 